\title{
BreastCore
}

\section{Breast Cancer Is Our Global Responsibility}

\author{
Nadia Harbeck ${ }^{\mathrm{a}}$ Michael Gnant ${ }^{\mathrm{b}}$ Christoph Thomssen ${ }^{\mathrm{c}}$ \\ ${ }^{a}$ Breast Center, Department of Obstetrics and Gynecology, University of Munich, Germany; \\ ${ }^{b}$ Department of Surgery and Comprehensive Cancer Center Vienna, Medical University of Vienna, Austria; \\ ${ }^{\mathrm{c}}$ Department of Gynecology, Martin-Luther-University, Halle an der Saale, Germany
}

Breast cancer is a global problem. In 2012, more than 1.5 million women were newly diagnosed with this disease worldwide, and about half a million women died from the disease (www.globocan.iarc.fr). Incidence and mortality rates differ greatly between countries and world regions. Whereas incidence as well as mortality tend to decrease in several European countries or Canada, both are still rising in some South American countries [1] and other parts of the world. The CONCORD 2 survey included more than 5.5 million women from about 200 registries in more than 50 countries for the recent report in 2015. For women diagnosed between 2005 and 2009, the 5 -year survival was $80 \%$ or more in 34 countries around the globe. Yet, in some countries 5-year survival still was substantially lower, in particular in India, some Asian countries or in South Africa [2].

We as the editors-in-chief have therefore invited several international colleagues to write about breast cancer incidence and mortality in their region of the world for this last issue of BREAST CARE in the year 2015. Fan and colleagues [3] discuss the situation in Asia while E. Kantelhardt and her colleagues [4] focus on breast cancer in Africa. Both regional situations are not widely known in European countries, and thus these reports may help to further our understanding for breast cancer as a global problem.

Our current scientific and clinical approach of breast cancer in the Western world is based on subgrouping the disease into more and more refined molecular subgroups that subsequently are to be treated according to their tumor biology with newly developed tar- geted agents. However, breast cancer awareness, screening, current therapy strategies, availability of molecular typing as well as access to new treatment options differ substantially between different nations. We are convinced that it is therefore also our responsibility to ensure that patients in other parts of the world are not being left behind. At present, even simple steps would help a lot: for example, quality assured routine estrogen receptor determination and adjuvant tamoxifen therapy (monthly costs: $9 €$ ) which is not routine in many countries, may reduce long-term mortality by $1 / 3$.

Fortunately, current international guidelines, such as the St. Gallen conference for early breast cancer $[5,6]$ or even more so $\mathrm{ABC}$ in Lisbon for the advanced setting $[7,8]$, are already considering these international differences by proposing so-called 'minimal standards of care' that can be followed worldwide. Moreover, new criteria and scales for evaluating and scoring the added value of new drugs published by the American Society of Clinical Oncology (ASCO) [9] and the European Society for Medical Oncology (ESMO) [10], aim to assess new drugs on a global level for their true added benefit compared to current standards of care. These frameworks aim to provide objective criteria beyond national boundaries and may thus indeed be helpful to ensure access to truly innovative compounds in countries with limited resources.

In short: breast cancer will remain a global problem and it is our responsibility to support global solutions that will benefit patients worldwide.

\section{References}

1 DeSantis CE, Bray F, Ferlay J, et al.: International variation in female breast cancer incidence and mortality rates. Cancer Epidemiol Biomarkers Prev 2015;24:1495-1506.

- Allemani C, Weir HK, Carreira H, et al.; CONCORD Working Group: Global surveillance of cancer survival 1995-2009: analysis of individual data for $25,676,887$ patients from 279 population-based registries in 67 countries (CONCORD-2). Lancet 2015;385:977-1010.

3 Fan L, Goss P, Strasser-Weippl K: Current status and future projections of breast cancer in Asia. Breast Care 2015;10: DOI: 10.1159/000441818.

4 Kantelhardt EJ, Muluken G, Sefonias G, et al.: A review on breast cancer care in Africa. Breast Care 2015;10: DOI: $10.1159 / 000443156$.
5 Coates AS, Winer EP, Goldhirsch A, et al.; Panel Members: Tailoring therapies - improving the management of early breast cancer: St Gallen International Expert Consensus on the Primary Therapy of Early Breast Cancer 2015. Ann Oncol 2015;26:1533-1546.

6 Senn HJ: St Gallen consensus 2013: optimizing and personalizing primary curative therapy for breast cancer worldwide. Breast Care 2013;8:101.

7 Cardoso F, Costa A, Norton L, et al.; European School of Oncology; European Society of Medical Oncology: ESOESMO 2nd international consensus guidelines for advanced breast cancer (ABC2). Breast 2014;23:489-502.

$\checkmark 8$ Thomssen C, Harbeck N: ABC2 Consensus Conference on Advanced Breast Cancer: brief summary of the consensus panel on Saturday November 9, 2013. Breast Care 2013;8:455-456.

9 Schnipper LE, Davidson NE, Wollins DS, et al., American Society of Clinical Oncology: American Society of Clinical Oncology statement: a conceptual framework to assess the value of cancer treatment options. J Clin Oncol. 2015;33:2563-2577.

10 Cherny NI, Sullivan R, Dafni U, et al.: A standardised, generic, validated approach to stratify the magnitude of clinical benefit that can be anticipated from anticancer therapies: the European Society for Medical Oncology Magnitude of Clinical Benefit Scale (ESMOMCBS). Ann Oncol 2015;26:1547-1573.

\section{KARGER}

(๑) 2015 S. Karger GmbH, Freiburg

Fax +497614520714 (c) 2015 S. Karger GmbH, Freiburg
$1661-3791 / 15 / 0106-0360 \$ 39.50 / 0$

Accessible online at:

www.karger.com/brc
Univ.-Prof. Dr. med. Nadia Harbeck

Brustzentrum der Universität München

Frauenkliniken Maistrasse-Innenstadt und Großhader

Marchioninistrasse 15, 81377 München, Germany

Nadia.Harbeck@med.uni-muenchen.de 